\title{
Research Paper: The Effectiveness of Mindfulness- Based Internet Intervention on the Anxiety, Depression, and Fatigue of the Patients With Multiple Sclerosis
}

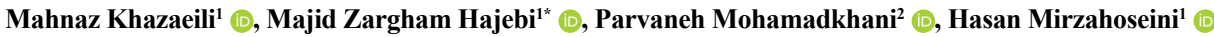 \\ 1. Department of General Psychology, Faculty of Human Sciences, Qom Branch, Islamic Azad University, Qom, Iran. \\ 2. Department of Clinical Psychology, University of Social Welfare and Rehabilitation Sciences, Tehran, Iran.
}

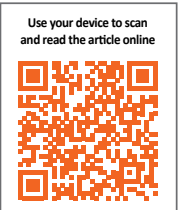

ditention: Khazaeili, M., Zargham Hajebi, M., Mohamadkhani, P., \& Mirzahoseini, H. (2019). The Effectiveness of Mindfulness-Based Internet Intervention on the Anxiety, Depression, and Fatigue of the Patients With Multiple Sclerosis. Journal of Practice in Clinical Psychology, 7(2), 137-146. http://dx.doi.org/10.32598/jpcp.7.2.137

http://dx.doi.org/10.32598/jpcp.7.2.137

\section{Keywords:}

Mindfulness-base, Internet, Intervention, Multiple Sclerosis, Anxiety, Depression, Fatigue

\begin{abstract}
Objective: Multiple Sclerosis (MS) is one of the prevalent autoimmune diseases that affects the central nervous system. It is a chronic neurological disorder that progresses to physical inability and cognitive abnormalities restricting the individual's ability to function independently. The problems of MS patients significantly affect their psychological well-being. Considering the problems of MS patients, like commuting, traffic, and long distances to health centers, weather conditions, and enormous time and costs they spend on seeking health services, remote psychological intervention is an alternative and advisable choice. This study aimed to investigate the effect of a Mindfulness-Based Intervention (MBI) via a web conferencing application on the reduction of anxiety, depression, and fatigue of patients with MS.
\end{abstract}

Methods: This is a pre-test post-test quasi-experimental study with a control group. A total of 30 female patients with relapsing-remitting MS, who met the inclusion criteria were selected through purposeful sampling method from the members of the MS Society in Tehran and Qom cities in 2017. They were randomly divided into experimental $(n=15)$ and control groups $(n=15)$. The two groups completed Beck anxiety inventory, Beck depression inventory, and fatigue Inventory online in three stages (before the intervention, after the intervention, and one-month follow-up after intervention). The experimental group received eight 2-h sessions of MBI via a web conferencing software, while the control group received no intervention. For analyzing the collected data, repeated-measures multivariate analysis of variance was performed in SPSS V. 23.

Results: There was a significant difference between the two groups in the post-test scores of anxiety $\left(\mathrm{F}=50.277, \mathrm{P} \leq 0.001, \eta^{2}=0.642\right)$, depression $\left(\mathrm{F}=73.680, \mathrm{P} \leq 0.001, \eta^{2}=0.725\right)$, and fatigue $\left(\mathrm{F}=111.086, \mathrm{P} \leq 0.001, \eta^{2}=0.799\right)$. $\mathrm{MBI}$ significantly reduced the anxiety and depression and fatigue in the experimental group.

Conclusion: MBI is effective in reducing anxiety, depression, and fatigue of MS patients. This therapy can be applied as an effective method to improve the quality of life of MS patients.

\section{* Corresponding Author:}

Majid Zargham Hajebi, PhD

Address: Department of General Psychology, Faculty of Human Sciences, Qom Branch, Islamic Azad University, Qom, Iran.

Tel: +98 (912) 5518790

E-mail: zarghamhajebi@gmail.com 


\section{Highlights}

- The problems of patients with multiple sclerosis significantly affect their psychological well-being.

- These patients suffer from anxiety, depression, and fatigue.

-Considering the problems of MS patients, remote psychological intervention seems to be necessary.

- Mindfulness-based tele-derived intervention via a web conferencing application can reduce anxiety, depression, and fatigue of the patients with multiple sclerosis.

\section{Plain Language Summary}

Problems of patients with multiple sclerosis significantly affect their psychological health. This condition causes anxiety, depression, fatigue, and so on in them. Considering problems such as long distances to health centers and time and costs spent, the need for remote psychological intervention, for example, via the Internet and web conferencing applications, is necessary. In this regard, we provided training, practices, and homework by mindfulness-based internet intervention via a web conferencing application for a sample of patients with multiple sclerosis. The outcome was positively useful in lowering their anxiety, depression, and fatigue.

\section{Introduction}

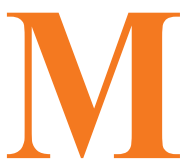

ultiple Sclerosis (MS) is one of the common diseases of the autoimmune system that affects the central nervous system (McCabe, 2005). Studies show that MS patients and their families suffer from a wide range of mental disorders such as stress, mood disorder, anxiety, depression, and fatigue (Cavalera et al., 2016). E-health technologies help people to get easier access to care services and enjoy better quality of services too. The Internet is now available via smartphones, and most people can use it. The advancement of digital applications and technologies for MS patients has been very fast in recent years. These applications aim at completing conventional inter-clinical methods and can have significant benefits for patients and healthcare providers. These benefits are essential because MS requires ongoing treatment and monitoring (Marziniak et al., 2018).

Distance learning by using various media can be considered as a systematic process for providing training to learners in their workplaces or houses who are separated from each other in time and space (Gharabaghi \& Talaei Mashoof, 2009). Information and communication technology has undoubtedly led to widespread developments in all social and economic aspects of human life. The extent of its application in various aspects of the present and future life of human societies has become one of the most important priorities in the world (Gharabaghi \& Talaei Mashoof, 2009).
Remote therapy, telemental health applications, or internetbased psychotherapy, is a form of psychotherapy or related psychological practice in which a trained psychotherapist meets with a client or patient via telephone, cellular phone, the Internet or other electronic media in addition to conventional face-to-face psychotherapy. Remote therapy can overcome some of the barriers to psychological treatment Telephone interventions have some benefits because they are accessible to all and easy to work with; this creates an opportunity for people who may not have access to personal care (Hailey, Roine, and Ohinmaa, 2008).

Mindfulness-Based Intervention (MBI) is a stress-relief technique that reduces the cognitive dysfunction and the burden of symptoms and improves quality of life for both the MS patients and their families. Non-attendant treatments are essential because problems may occur through face-to-face treatment such as traveling long distances, and patients' inability to move and attend all treatment sessions. Remote intervention is for preventing commuting problems, better accessing, and cost reduction (Frontario, Feld, Sherman, Krupp, \& Charvet, 2016). MBI by using webbased applications can reduce patients' anxiety and stress, and improve their health. Studies have shown that MBI can improve the psychological health of MS patients and their caregivers and overcome their mental pains (Cavalera et al., 2016).

According to the literature, there are studies about telemedicine via communication technologies (Shirazi et al., 2017; Ahmadi, 2018), and face to face mindfulness intervention 
(Farhadi, \& Pasandideh, 2017; Ahmadi, 2018) in Iran but lack of studies on internet-based mindfulness intervention for MS patients and their caregivers is noticeable.

According to Kabat-Zinn (1990), mindfulness means "paying attention in a particular way, on purpose, in the present moment, and non-judgmentally". Segal, and Williams (2002) used mindfulness-based therapy in an eightsession program to bolster recovery from depression and prevent relapse. They showed that higher mindfulness is associated with a variety of health outcomes such as reducing pain, anxiety, depression, pathological eating, and stress. It can help people stop automatic thoughts, habits, and unhealthy behavioral patterns, and thus play an important role in regulating behavior. Many psychopathology and psychotherapy theories have discussed the importance of awareness, presence, and observation in mental health (Hollon, 2006).

Presented by Segal, and Williams (2002), mindfulnessbased cognitive therapy is a combination of meditation, yoga, and cognitive therapy to help people gain awareness of their mental states of sadness and prevent it from spiraling out of control. It is based on meditation exercises for the presence of the mind. In other words, patients with MS, besides targeting MS main symptoms, need treatments that aim other problems so that they can deal with the disease with higher mental health (Aghabagheri, Mohammadkhani, Omrani, \& Farahmand, 2012).

In traditional cognitive therapy, the content of irrational thoughts is tested to change them. When trying to change the content of thoughts, the relationship of individuals with their thoughts may also be affected. Overall, recognizing negative thoughts help people to change their view of negative thoughts and feelings.

Various studies have supported the efficacy of MBI. For example, a randomized controlled trial in Italy (Cavalera et al., 2016) investigated the impact of an MS-specific telemedicine meditation on the quality of life of patients with MS. This trial recruited 120 patients, from both genders, with a diagnosis of relapsing-remitting or secondary progressive MS to participate in a 2-month intervention. The patients underwent an assessment of their quality of life, anxiety, depression, quality of sleep, mindfulness, and fatigue levels at baseline, at week 8 (conclusion of the intervention), and week 27 (6 months follow-up). The caregivers completed the assessments in the same areas, plus caregiver burden at the same time points. The intervention condition consisted of $2 \mathrm{~h} / \mathrm{wk}$ of online meditation in a group setting led by a trainer, plus $1 \mathrm{~h} / \mathrm{wk}$ of individual exercises. The control condition incorporated a psycho-education online program and required the same contact time commitment as the intervention condition. The results indicated an improvement in the quality of life, a decrease in the anxiety and depression, an attained mindfulness level, a reduction in sleep disturbance and fatigue in the patients with MS and their caregivers and decrease in caregivers' burden.

Another similar study, where the impact of a telemedicine MBI on the quality of life of people with MS was investigated, showed a reduction in sleep disturbance and better quality of life both in the patients with MS and their caregivers (Pagnin, 2017). Ershad Sarabi et al. (2017) reported that mobile technology provided new opportunities for health care systems. Improvement of health services outcomes in different patient groups is one of the benefits of using this tool. Although the use of mobile in Iran is expanding, there is little information on the state and the use of this technology in the health system. Their study aimed to review published researches on the application of mHealth (Mobile health) in the health system of Iran. To carry out a review study, PubMed database was searched by the keyword "Mobile Health". and its equivalents, derived from the "Medical Subject Headings".

Iranian databases, including Iran medex, Magiran, and Scientific Information Database (SID) were also searched for Persian and English terms of mobile health. Retrieval citations from information databases were sent to the endnote software and evaluated based on the considered criteria. The research sample consisted of 26 articles that met the study criteria. In most studies, text messaging was the main intervention tool of mHealth. The results indicated a significant effect of mobile health in improving the patients' care. In Iran, mobile health can be effectively used in the health system due to the population structure of users and its geographic extent. According to the results of this study, the use of mobile health, especially in educating patients for self-care and preventing the spread of diseases, can be very useful.

Internet-based mindfulness training and cognitive-behavior training with telephone support hold promising results in improving the mental health among college students and young working adults (Mak, Chio, Chan, Lui, \& Wu, 2017). Marziniak et al. (2018) reported that digital applications and remote communication technologies for MS patients had increased rapidly in recent years for reasons such as mobility restrictions, travel costs, consultation and treatment time constraints, and a lack of locally available MS expert services.

In this randomized controlled trial, the study patients were recruited from an outpatient clinic in Hamburg, Germany. 
The patients were 18-65 years old with MS and self-reported depressive symptoms. A computer-generated randomization sequence allocated 90 patients (1:1; no blocking or stratification) to either the intervention group or a waiting list group for 9 weeks. The primary endpoint was the Beck Depression Inventory (BDI), as assessed by intention-totreat analysis. Seventy-one patients completed the trial: 35 patients in the intervention group and 36 patients in the control group. During the intervention, BDI scores decreased in the Deprexis group and increased in the control group, yielding a positive effect of Deprexis relative to the waiting list group (mean group difference -4.02 points, $95 \%$ CI: 7.26 to $-0.79, \mathrm{P}=0.015$, effect size $\mathrm{d}=0.53$ ). Worsening of depressive symptoms from below to above the clinical cutoff (BDI $>13$ ) occurred in three $(7 \%)$ of 45 patients in the control group and no patients in the Deprexis group. We noted no adverse events concerning the new occurrence of suicidal ideation during the trial (Fischer, 2015).

Health-Related Quality of Life (HRQOL) often reduces among individuals with MS, and incidence rates of depression, fatigue, and anxiety are high. We examined the effects of a Mindfulness-Based Intervention (MBI) compared to Usual Care (UC) upon HRQOL, depression, and fatigue among adults with relapsing-remitting or secondary progressive MS. A total of 150 patients were randomly assigned to the intervention $(n=76)$ or to $U C(n=74)$. MBI consisted of a structured 8-week program of mindfulness training. Assessments were made at baseline, post-intervention, and 6 months follow-up. Primary outcomes included disease-specific and disease-unspecific HRQOL, depression, and fatigue. Anxiety, personal goal attainment, and adherence to homework were secondary outcomes (Grossman, Niemann, Schmidt, \& Walach, 2004).

Firoozi and Ramezani Piyani (2018) showed that positive psychological interventions based on virtual social networks are effective on anxiety and depression reduction of patients with spinal cord injury. In another study, the effectiveness of remote nursing through telephone consultation was investigated on the rate of depression and anxiety in family caregivers in patients with stroke (Goodarzian, 2016). The caregivers receiving telephone counseling showed lower levels of anxiety.

Problems of MS patients significantly affect their mental health and the caregivers'. Considering the difficulties in face-to-face treatment and the advent of technology and communication technology, especially the Internet in the field of psychology and psychotherapy, these interventions can now be conducted remotely using the internet-based applications. So far, psychological internet-based interventions have not been done for MS patients in Iran. In this regard, this study aimed to investigate the effect of internetbased mindfulness training on anxiety, depression, and fatigue of MS patients.

\section{Methods}

This is a pre-test, post-test quasi-experimental study with a control group. The independent variable is remote MBI, where dependent variables are anxiety, depression, and fatigue. The study population consisted of women with Relapsing-Remitting MS (RRMS) who were members of the Iranian MS Society in Tehran and Qom cities in 2017. Of them, 30 were selected using purposeful sampling method. For sampling, first, the documents and an introduction letter were presented to the director and research department of the MS Society in Tehran and Qom. Then, the researcher participated in one of the patients' rounds and a form that contained questions about demographic information, anxiety, depression records, and inclusion criteria were given to the members to complete. Since the ideal sample size in a study with an experimental design is 15 (Biyabangard, 2011), 15 eligible patients were selected from Tehran and 15 from Qom (total sample size $=30$ ).

They were randomly assigned to the experimental and control groups. The inclusion criteria were as follows: able to communicate and understand tasks; access to relatively high-speed internet, have a personal computer or mobile phone, have enough literacy, and aged 20-40 years. Moreover, the exclusion criteria were as follows: having severe physical problems such as heart disease reported by physicians, or mental illness and addiction; failure to communicate and understand the tasks; lacking access to the Internet, computer, tablet, or a mobile phone; and unwilling to participate in the sessions.

The patients in the experimental group were invited to attend a meeting at the MS Society in Tehran and Qom. In this meeting, while getting acquainted and obtaining informed consent and assuring of information confidentiality, they were informed about the procedure and objectives of an 8-week mindfulness-based program. They were told that they would be added to a group in the Telegram application to receive educational notes and audio files. In the pre-test phase, the questionnaires were sent via Telegram to the caregivers of the study patients in both groups at the same time, and they were sent the questionnaires back after completion.

The patients in the control group received no intervention. Again, all groups filled out the questionnaires at the same time one week after the end of the intervention (post-test 
phase). A follow-up study was conducted one month after the implementation of the post-test.

Independent variable is remote MBI, where dependent variables are anxiety, depression, and fatigue. For gathering data related to literature, library method was used, and data from the participants were gathered online via Telegram. The web conferencing software was Adobe Connect V. 9. 6. This software has many advantages, including connecting up to 30 users simultaneously and exchanging hours of video and audio communications without being disconnected. Many universities in Iran use this software. The patients in the control group received no intervention.

Beck Anxiety Inventory, Second Edition (BAI-II) (Beck, 1990) has 21 items surveying common symptoms of anxiety (mental, physical and panic-related) based on a 4-point Likert-type scale from 0 to 3 ( $0=$ not at all, $1=$ mild, $2=$ moderate, $3=$ severe). Total score can range between 0 and 63 points (Key, 217). A total score of 0-7 is interpreted as a "minimal", 8-15 as "mild", 16-25 as "moderate", and 26-63 as "severe". level of anxiety". Studies have shown that this questionnaire has high reliability and validity. Its internal consistency coefficient has been reported as 0.92 , while its test-retest reliability with a one-week interval was 0.75 , and the correlation of its items ranges from 0.30 to 0.70 (Askarizadeh, Karamoozian, \& Darekordi, 2017).

Checking five types of content validity, concurrent validity, construct validity, diagnostic validity, and Beck, anxiety scale factor, have indicated the effectiveness of this tool for the Iranian population. Kaviani and Mousavi reported for this tool, the internal consistency coefficient of 0.72 , testretest reliability with a one-month interval as 0.83 , and a Cronbach alpha of 0.92 . The reliability of this tool has been reported from 0.80 to 0.92 . In a study on the Iranian students, the reliability of this questionnaire was reported as 0.92 using Cronbach alpha coefficient (Beck, Epstein, Brown, \& Steer, 1988; Beck \& Steer, 1990).

Beck Depression Inventory, Second Edition (BDI-II) (Beck et al., 1988) is a 21-item self-report inventory for measuring the severity of depression. It is scored on a 4-point Likert-type scale from 0 to $3(0=$ not at all, $1=$ mild, $2=$ moderate, $3=$ severe). Total score ranges between 0 and 63 points; the highest score indicates the severe level of depression (Lee et al., 2017). Its reliability and validity have been confirmed in several studies. Beck et al. (1988) reported its internal consistency from 0.73 to 0.92 based on the Cronbach alpha calculation, and the coefficients of its test-retest reliability were 0.48 to 0.68 . The correlation coefficient of the Beck Depression Inventory (BDI) with the Hamilton depression rating scale is 0.73 .
The results of a meta-analysis on the BDI show that its internal consistency coefficient ranges from 0.73 to 0.93 , with an average of 0.86. Ghasemzadeh et al. (2005) reported that the Cronbach alpha coefficient of BDI for normal subjects was 0.85 to 0.92 , and for a sample of patients, 0.83 to 0.91 , indicating good internal consistency. The correlation coefficients between the scores of normal and patient subjects for measuring test-retest reliability were obtained as 0.81 and 0.79 , respectively. The recommended cutoff point in this test for minimal depression is $0-13$; for mild depression 14-19; for moderate depression 20-28; and for severe depression 29-63 (Fathi Ashtiani, 2011).

The Mindfulness-Based Intervention (MBI) included an 8 -session ( 2 hours per session) program (a combination of mindfulness-based cognitive therapy and mindfulnessbased stress reduction) provided remotely via web conferencing. The MBI program content was as follows: Session 1. Identification of autopilot and breaking out of it, mindfulness of daily activities, and body scan; Session 2. Dealing with barriers, reaction to daily events, a list of enjoyable activities, and 10-min sitting meditation; Session 3. Awareness of thought, gathering attention, 40-min breath-focused or body-focused sitting meditation, and unpleasant body feelings; Session 4. Staying at present, attachment and aversion; Session 5. Acceptance of individual experiences; Session 6. Thoughts are not facts; Session 7. How we can care for ourselves: A list of enjoyable and skillful activities, a list of signs and symptoms of depression, providing an activity plan for coping with depression, practicing how to say goodbye; and Session 8. A pplying what was learned to deal with people in the future (Kabatzin, 1993; Teasdale, Segal \& Williams, 1995; quoted by Mohamadkhani, and Khanipore, 2012).

The collected data were analyzed in SPSS V. 23. The variables were first evaluated by performing descriptive statistics such as Mean \pm SD. For testing research hypotheses, and significance of the difference between mean scores, repeated-measures Multivariate Analysis of Variance (MANOVA) were used since there are three dependent variables for the study.

\section{Results}

In this section, first, we present descriptive statistics of study variables, and then results of the inferential test. Table 1 presents descriptive statistics for anxiety, depression, and fatigue in three phases of pre-test, post-test, and followup. It can be seen that the mean of pre-test scores of these variables in the control and test groups are close to each other, indicating the homogeneity of these two groups and the random assigning of individuals in these two groups. It 
is also observed that the mean scores of all three variables are similar in the control group in all three stages and do not change considerably.

On the contrary, the mean scores in the experimental group decreased. Results of the repeated-measures Multivariate Analysis of Variance (MANOVA) test are presented in Table 2. Before the test, the normal distribution assumption was investigated using the Shapiro-Wilk test, and homogeneity by using Levene's test, whose results were confirmed. Also, results of Mauchly's test for testing the assumption of sphericity (equality of the variances of the difference between subjects) showed significant differences between the variances of the differences; hence, sphericity cannot be assumed. In this regard, for performing repeated-measures MANOVA test, the degree of freedom correction was done and, given that the amount of Mauchly's test statistic was less than 0.751, the Huynh-Feldt adjustment was used.

Results of Table 2 show that the effect of measurement time on anxiety is significant $(\mathrm{F}=51.797, \mathrm{P}<0.001$, $\eta^{2}=0.649$ ). In other words, there is a significant difference between the mean scores of anxiety in the three stages of pre-test, post-test, and follow-up, regardless of the group factor. The group influence is also significant $(\mathrm{F}=12.082$, $\left.\mathrm{P}<0.01 ; \eta^{2}=0.301\right)$. In other words, there is a significant difference between the mean anxiety scores in the test and control groups, irrespective of the measurement time. Furthermore, the effect of interaction between the group and the measurement time was significant $(\mathrm{F}=50.277, \mathrm{P}<0.001$, $\eta^{2}=0.642$ ). Therefore, there is a significant difference between the mean anxiety of caregivers in both groups in the pre-test, post-test, and follow-up phases.

Results related to depression variable in Table 2 show that the effect of measuring time on depression scores is significant $\left(\mathrm{F}=73.680, \mathrm{P}<0.001, \eta^{2}=0.725\right)$. In other words, there is a significant difference between the mean scores of depression in the three stages of pre-test, post-test, and follow-up regardless of the group factor. Also, the effect of group was significant $\left(\mathrm{F}=21.527, \mathrm{P}<0.001, \eta^{2}=0.435\right)$. As a result, there is a significant difference between mean scores of depression in both groups. Moreover, the effect of interaction between the group and the measurement time was also significant $\left(\mathrm{F}=68.773, \mathrm{P}<0.001, \eta^{2}=0.711\right)$. So, there is a significant difference between the mean depression of patients both in groups in the pre-test, post-test, and followup stages.

Results of fatigue revealed that the effect of measurement time on fatigue scores is significant $(\mathrm{F}=111.086, \mathrm{P}<0.001$, $\left.\eta^{2}=0.799\right)$. In other words, there is a significant difference between the mean scores of fatigue in the three stages of pre-test, post-test and follow-up regardless of the group factor. Also, there is a significant difference between the mean scores of fatigue in the test and control groups irrespective of the measurement time $\left(\mathrm{F}=31.829, \mathrm{P}<0.001, \eta^{2}=0.532\right)$. Moreover, based on the interaction between the group and the measurement time, there is a significant difference between the mean scores of fatigue in test and control groups in the pre-test, post-test, and follow-up stages of measurements $\left(\mathrm{F}=1131.179, \mathrm{P}<0.001, \eta^{2}=0.802\right)$.

According to Bonferroni post hoc test results, the difference of the pre-test scores with post-test and follow-up scores was significant at $\mathrm{P}<0.001$ level which indicates the effect of the remote mindfulness training on the reduction of anxiety, depression, and fatigue. A little difference was observed between post-test and follow-up scores, which indicates that the effect of MBI is sustainable and has not diminished.

\section{Discussion}

Table 1. Descriptive statistics of study variables in three phases

\begin{tabular}{|c|c|c|c|c|}
\hline \multirow[b]{2}{*}{ Variables } & \multirow{2}{*}{ Group } & \multicolumn{3}{|c|}{ Mean $\pm S D$} \\
\hline & & Pre-test & Post-test & Follow-up \\
\hline \multirow{3}{*}{ Anxiety } & Test & $27.6 \pm 12.2$ & $9.33 \pm 4.35$ & $9.46 \pm 3.81$ \\
\hline & & & & \\
\hline & Control & $25 \pm 27.8$ & $24.86 \pm 8.00$ & $24.86 \pm 8.00$ \\
\hline \multirow{3}{*}{ Depression } & Experimental & $16.8 \pm 6.01$ & $5.4 \pm 2.79$ & $5 \pm 2.53$ \\
\hline & & & & \\
\hline & Control & $14.9 \pm 4.0$ & $14.73 \pm 3.23$ & $14.74 \pm 3.24$ \\
\hline \multirow{2}{*}{ Fatigue } & Experimental & $42.6 \pm 10.8$ & $19.4 \pm 3.48$ & $18.73 \pm 3.08$ \\
\hline & Control & $46.0 \pm 12.1$ & $45.93+12.04$ & $46.4 \pm 11.80$ \\
\hline
\end{tabular}


Table 2. Repeated-measures MANOVA results of anxiety, depression, fatigue

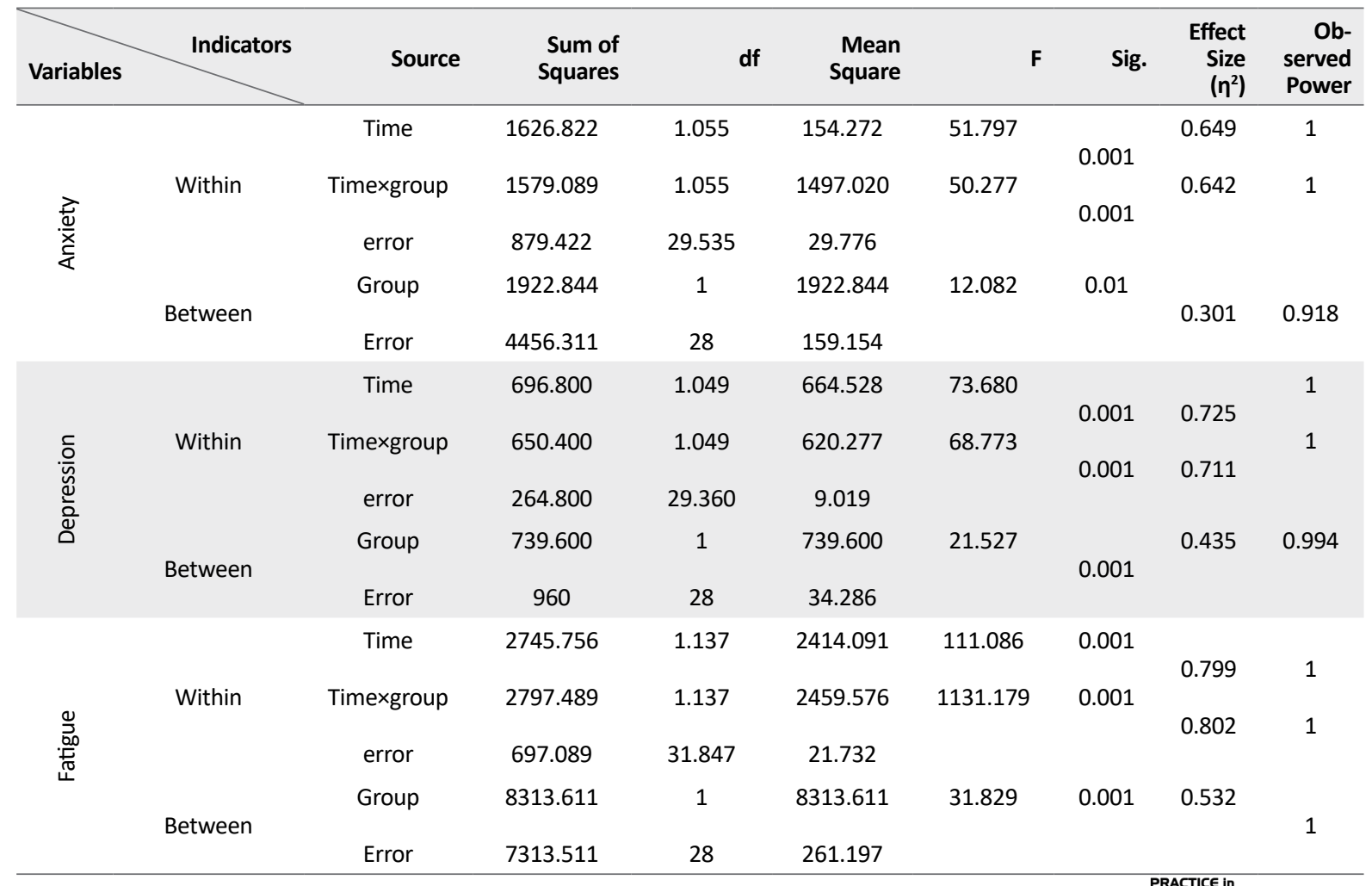

Results of our study indicate a significant difference between the experimental and control groups in the posttest scores of anxiety, depression, and fatigue. Therefore, MBI through web conferencing has reduced the anxiety and depression and fatigue of MS patients. According to the findings, there was a significant difference between the experimental and control groups after the intervention in terms of anxiety, depression, and fatigue. This finding is consistent with the results of other studies. Cavalera et al. (2016), Pagnini (2017), Marziniak et al. (2018), Dent et al. (2018), showed that anxiety, depression, and fatigue of MS patients reduced by administering internet-based MBI. They concluded that telemedicine and online mindfulness training, as a mediating factor, would play an important role in reducing the symptoms and would lead to positive outcomes when accepted by patients.

In explaining the reduction of depression after MBI, it can be said that the mindfulness through emotional regulation reduces the rumination of depression. Mindfulness-based cognitive therapy provides a different way of dealing with emotions and distress. Ignoring negative thoughts helps a person avoid engaging in mental ruminations (Mak, 2006; cited in Kahrizi \& et al., 2017). In mindfulness training, people realize the connection between thoughts, feelings, and body sensations at any time (Mohamadkhani and
Tamanayifar, 2005). Based on this awareness, thoughts and depressive states are detected, and by accepting these thoughts, depression gradually decreases. Effective mechanisms of mindfulness, such as exposure, cognitive change, self-management, relaxation, and acceptance, reduce symptoms of depression (Omidi \& Mohamadkhani, 2008). In other words, people learn to be aware of their physical states, feelings, and thoughts at the moment.

During the training, the physical and mental defects are identified; the person learns to be aware of the occurrence of these thoughts and feelings, and instead of their rejection and control, accept them and keep them in the present moment. This acceptance reduces the negative burden of these states and prevents the development of symptoms and, subsequently, anxiety and depression in the individual. Because of the exercises of mindfulness, the participants live in the moment and are aware of bodily sensations and psychological feelings. They notice that their heart rate and respiration changes when they are in anxiety. As a result, they focus more on the body, which increases the awareness of the body, feelings, and thoughts associated with the anxiety. This awareness increases the sense of control over symptoms and subsequently leads to anxiety reduction. Mindfulness-based cognitive therapy and being in the moment is an 
effective way to reduce the anxiety, depression, and fatigue of the patients (Mohamadkhani and Tamanayifar, 2005).

They learn to recognize physical states, especially their respiratory states; and if they feel breathless due to psychological factors such as anxiety and depression, they can control them by meditation such as a 3-minute breathing space and other breathing-focused exercises. The results of this study showed decreased anxiety, depression, and fatigue after 8 sessions of MBI, which is in agreement with these findings (Mohamadkhani and Tamanayifar, 2005).Considering the previous efforts on applying new telecommunication technologies to support psychological interventions, in this study, MBI was provided for MS patients remotely via an online application which could create the possibility of meditation at home to reduce their anxiety, depression, and fatigue. Review of the literature shows studies on the effectiveness of meditation on the mental well-being of MS patients (Grossman et al, 2004).

Participation in meditation can be prevented by practical reasons (e.g. occupational activities) or physical constraints. MS patients often suffer from mental illnesses. Few studies have examined the impact of psychological interventions on them. This study allows us to examine whether this treatment method can improve their quality of life or not. This intervention provides the ability to access easily to online resources, which can be an evidence-based approach to enhance the quality of life for MS patients. This protocol describes the development of a mindfulness intervention and its feasibility using a randomized controlled trial.

In this study, only a small sample of women participated. We recommend that future investigations be done with bigger sample sizes, including men. Another study limitation was the short follow-up period due to time constraints. It is suggested that a more extended follow-up period be used in future studies to evaluate the sustained effect of treatment. The villages and deprived areas should be equipped with high-speed internet. In this regard, medical teams, medical centers, or universities should be ready to coordinate and provide regular online services. Due to the importance of privacy and confidentiality, a private online security system should be designed for these people, and in the case of online filing, ethical protocols should be designed to protect them.

\section{Ethical Considerations}

\section{Compliance with ethical guidelines}

All ethical principles were considered in this article. The participants were informed about the purpose of the research and its implementation stages; they were also assured about the confidentiality of their information; Moreover, They were allowed to leave the study whenever they wish, and if desired, the results of the research would be available to them.

\section{Funding}

This research did not receive any specific grant from funding agencies in the public, commercial, or not-forprofit sectors

\section{Authors' contributions}

All authors contributed in designing, running, and writing all parts of the research.

\section{Conflict of interest}

The authors declared no conflict of interest.

\section{References}

Aghabagheri, H., Mohammadkhani, P., Omrani, S. \& Farahmand V. (2012). The efficacy of mindfulness-based cognitive therapy group on the increase of subjective well-being and hope in patients with multiple sclerosis. Journal of Clinical Psychology, 4(1), 23-31

Ahmadi-shooli, P., Feily, A. R., \& Behzadipour, S. (2016). [The effect of mindfulness-based cognitive therapy on the mental health of female patients suffering from multiple sclerosis (Persian)]. Journal of Shahid Sadoughi University of Medical Sciences, 23(10) 989-1000.

Ashford, M. T., Olander, E. K., \& Ayers, S. (2016). Finding webbased anxiety interventions on the world wide web: A scoping review. JMIR Mental Health, 3(2), e14. [DOI:10.2196/mental.5349] [PMID] [PMCID]

Askarizadeh, G., Karamoozian, M., \& Darekordi, A. (2017). Validation of Iranian version of pregnancy related anxiety questionnaire. International Journal of Preventive Medicine, 8:17. [DOI:10.4103/ijpvm.IJPVM_63_16] [PMID] [PMCID]

Beck, A. T. (1990). The Beck anxiety inventory manual. San Antonio: Psychologyical corporation.

Beck, A. T., Epstein, N., Brown, G., \& Steer, R. A. (1988). An inventory for measuring clinical anxiety: Psychometric properties. Journal of Consulting and Clinical Psychology, 56(6), 893-7. [DOI:10.1037/0022-006X.56.6.893] [PMID]

Beck, A. T., Steer, R. A. (1990). The Beck anxiety inventory manual. San Antonio: Psychologyical corporation.

Biyabangard, E. (2011). [The methods of research in psychology and educational science (Persian)]. Tehran: Doran.

Boeschoten, R. E., Dekker, J., Uitdehaag, B. M., Beekman, A. T., Hoogendoorn, A. W., Collette, E. H., et al. (2017). Internet- 
based treatment for depression in multiple sclerosis: A randomized controlled trial. Multiple Sclerosis Journal, 23(8), 1112-22. [DOI:10.1177/1352458516671820] [PMID]

Campos, D., Mira, A., Bretón-López, J., Castilla, D., Botella, C., Baños, R. M., et al. (2018). The acceptability of an internet-based exposure treatment for flying phobia with and without therapist guidance: Patients' expectations, satisfaction, treatment preferences, and usability. Neuropsychiatric Disease and Treatment, 14, 879-92. [DOI:10.2147/NDT.S153041] [PMID] [PMCID]

Carletto, S., Tesio, V., Borghi, M., Francone, D., Scavelli, F., Bertino, G., et al. (2017). The effectiveness of a body-affective mindfulness intervention for multiple sclerosis patients with depressive symptoms: A randomized controlled clinical trial. Frontiers in Psychology, 8, 2083. [DOI:10.3389/fpsyg.2017.02083] [PMID] [PMCID]

Carlson, L. E., Speca, M., Patel, K. D., \& Goodey, E. (2003). Mindfulness-based stress reduction in relation to quality of life, mood symptoms of stress, and immune parameters in breast and prostate cancer outpatients. Psychosomatic Medicine, 65(4), 571-81. [DOI:10.1097/01.PSY.0000074003.35911.41]

Cavalera, C., Pagnini, F., Rovaris, M., Mendozzi, L., Pugnetti, L., Garegnani, M., et al. (2016). A telemedicine meditation intervention for people with multiple sclerosis and their caregivers: Study protocol for a randomized controlled trial. Trials, 17, 4 . [DOI:10.1186/s13063-015-1136-9] [PMID] [PMCID]

Dent, L., Peters, A., Kerr, P. L., Mochari-Greenberger, H., \& Pande, R. L. (2018). Using telehealth to implement cognitive-behavioral therapy. Psychiatric Services, 69(4), 370-3. [DOI:10.1176/appi. ps.201700477] [PMID]

Deslich, S. A., Thistlethwaite, T., \& Coustasse, A. (2013). Telepsychiatry in correctional facilities: Using technology to improve access and decrease costs of mental health care in underserved populations. The Permanente Journal, 17(3), 80-94. [DOI:10.7812/ TPP/12-123] [PMID] [PMCID]

Ershad Sarabi, R., Sadoughi, F., Jamshidi Orak R., \& Bahaadinbeigy K. (2018). [Role of mobile technology in Iran healthcare system: A review study (Persian)]. Journal of Health and Biomedical Informatics; 4(4): 313-26

Farhadi, M., \& Pasandideh, M. M. (2018). Mindfulness based cognitive therapy in reducing stress, anxiety, depression and increase self-efficacy in female patients with Multiple Sclerosis (MS). Biannual Journal of Clinical Psychology \& Personality, 15(2), 7-15.

Feinstein, A., Magalhaes, S., Richard, J. F., Audet, B., \& Moore, C. (2014). The link between multiple sclerosis and depression. Nature Reviews Neurology, 10(9), 507-17. [DOI:10.1038/nrneurol.2014.139] [PMID]

Fathi Ashtiani, A. (2011). [Psychological test books: Personality assessment and mental health (Persian)]. Tehran: Be'sat.

Firoozi, M., \& Ramezani Piyani, M. (2018). [Effect of positive psychotherapy based on virtual social networks on anxiety and depression reduction in veterans with spinal cord injury. Iranian Journal of War \& Public Health (Persian)], 10(1), 21-6. [DOI:10.18869/acadpub.jiwph.10.1.21]

Frontario, A., Feld, E., Sherman, K., Krupp, L., \& Charvet, L. (2016). Telehealth mindfulness meditation improves cognitive performance in adults with Multiple Sclerosis (MS). Neurology, 86(16), P3-092.
Fiest, K. M., Walker, J. R., Bernstein, C. N., Graff, L. A., Zarychanski, R., \& Abou-Setta, A. M. (2015). Multiple sclerosis and related disorders. Multiple Sclerosis and Related Disorders, 5, 12-26. [DOI:10.1016/j.msard.2015.10.004] [PMID]

Firoozi, M., Ramezani, M. (2018). Effect of positive psychotherapy based on virtual social networks on anxiety and depression reduction in veterans with spinal cord injury. Iranian Journal of War \& Public Health, 10(1):21-6. [DOI:10.29252/ijwph.10.1.21]

Fischer, A., Schröder, J., Vettorazzi, E., Wolf, O. T., Pöttgen, J., Lau, S., et al. (2015). An online programme to reduce depression in patients with multiple sclerosis: A randomised controlled trial. The Lancet Psychiatry, 2(3), 217-23. [DOI:10.1016/S22150366(14)00049-2]

Friedemann, P. (2016). Online program to reduce depression in MS. Retrieved from https://clinicaltrials.gov/ct2/show/NCT02740361

Ghassemzadeh, H., Mojtabai, R., Karamghadiri, N., \& Ebrahimkhani, N. (2005). Psychometric properties of a Persian-language version of the Beck Depression Inventory-Second edition: BDIII-Persian. Depress Anxiety, 21(4), 185-92. [DOI:10.1002/da.20070] [PMID]

Griffiths, K. M., Farrer, L., \& Christensen, H. (2010). The efficacy of internet interventions for depression and anxiety disorders: A review of randomised controlled trials. Medical Journal of Australia, 192(S11), S4-S11. [DOI:10.5694/j.1326-5377.2010.tb03685.x]

Grossman, P., Niemann, L., Schmidt, S., \& Walach, H. (2004). Mindfulness-based stress reduction and health benefits: A meta-analysis. Journal of Psychosomatic Research, 57(1), 35-43. [DOI:10.1016/ S0022-3999(03)00573-7]

Gharabaghi, H., \& Talaei Mash'oof, A. A. (2009). [Theoretical basics of E-learning (Persian)]. Paper presented at The First E-Learning Student Conference, Tehran, Iran, 10-11 December 2009

Goodarzian, M. (2016). [The effectiveness of remote nursing through telephone consultation on the rate of depression and anxiety in family carers in patients with stroke (Persian)] [MSc. thesis]. Tehran: University of Social Welfare and Rehabilitation Sciences.

Hailey, D., Ohinmaa, A., Roine, R., \& Bulger,T. (2007). Uptake of telemental health services in Alberta: A success, but not in all regions. Journal of Telemedicine and Telecare, 15(5), 71-7.

Hirazi, E., Ahmadkhaniha, H., Sayahfar, Sh., Hosseini Shams Abadi, R., \& Afsharkhass, L. (2017). [Delivery of medical care by telehealth system (Persian)]. Razi Journal of Medical Sciences, $24(164), 9-12$.

Hollon, S. D., Stewart, M. O., Strunk, D. (2006). Enduring effects for cognitive behavior therapy in the treatment of depression and anxiety. Annual Review of Psychology, 57:285-315. [DOI: 10.2904.190044]

Kabat-Zinn, T., Nhat Hanh, Th. (2013). Full catastrophe living: Using wisdom of your body and mind to face stress, pain and illness. New York City: Bantam Books.

Kahrizi, S., Taghavi, M., Ghasemi, R., \& Goodarzi, M. (2017). [The effectiveness of Mindfulness-Based Cognitive Therapy (MBCT) on depression, anxiety and somatic symptoms in asthma patients (Persian)]. Razi Journal of Medical Sciences, 24(154) 27-36.

Ke, Y., Ng, T., Yeo, H. L., Shwe, M., Gan, Y. X., \& Chan, A. (2016) Psychometric properties and measurement equivalence of the English and Chinese versions of the Beck Anxiety Inventory in 
patients with breast cancer. Supportive Care in Cancer, 25(2), 63343. [DOI: 10.1007/s00520-016-3452-3] [PMID]

Krupp, L. B., Coyle, P. K., Doscher, C., Miller, A., Cross, A. H., Jandorf, L., .et al. (1995). Fatigue therapy in multiple sclerosis: Results of a double-blind, randomized, parallel trial of amantadine, pemoline, and placebo. Neurology, 45(11), 1956-61. [DOI:10.1212/ WNL.45.11.1956] [PMID]

Lee, E. H., Lee, S. J., Hwang, S.T., Hong, S. H., \& Kim, J. H. (2017). Relability and validity of the Beck Depression Inventory-II among Korean Adolescents . Psychiatry Investig, 14(1), 30-6

Marziniak, M., Brichetto, G., Feys, P., Meyding-Lamadé, U., Vernon, K., \& Meuth, S. G. (2018). The use of digital and remote communication technologies as a tool for multiple sclerosis management: narrative review. JMIR Rehabilitation and Assistive Technologies, 5(1), e5. [DOI:10.2196/rehab.7805] [PMID] [PMCID]

MCcabe, M. P. (2005). Mood and self-esteem of persons with multiple sclerosis following an exacerbation. Journal of Psychosomatic Research， 59(3)， 161-6.[DOI:10.1016/j.jpsychores.2005.04.010] [PMID]

Mehdipour, Y., Noori, T., Mehraeen, E., Khajepour, E., Balochzehi Shahbakhsh, F., \& Farhadi, E. (2015). [Utilization of telemental health services from the viewpoints of psychology students of Zahedan Universities (Persian)]. Journal of Health and Biomedical Informatics, 1(2), 122-30.

Mohamadkhani, P., \& Tamanayifar, S. (2005). [Mindfulness based cognitive therapy for depression (Persian)]. Tehran: Faradid.

Mohammadkhani, P., \& Khanipour, H. (2016). [Mindfulness Based cognitive therapies (Persian)]. Tehran: University of Social Welfare and Rehabilitation Sciences.

Mak, W. W., Chio, F., Chan, A., Lui, W., \& Wu, E. (2017). The efficacy of internet-based mindfulness training and cognitive-behavior traing with telephone support in the enhancement of mental health among college students and young working adults: Randomized controlled trial. Journal of Medical Internet Research, 19(3), e84. [DOI:10.2196/jmir.6737]

Mahmoodi, M., Mohammad Khani, P., Ghobari Banab, B., \& Bagheri, F. (2016). [Effectiveness of group cognitive-behavioral therapy on strategies for coping with stress of family caregivers of patients with alzheimer's disease (Persian)]. Iranian Journal of Ageing, 11(4), 190-201. [DOI:10.21859/sija-1101190]

Morland, L. A., Greene, C. J., Rosen, C. S., Foy, D., Reilly, P., Shore, J., et al. (2010). Telemedicine for anger management therapy in a rural population of combat veterans with posttraumatic stress disorder: A randomized noninferiority trial. The Journal of Clinical Psychiatry, 71(7), 855-63. [PMID]

Omidi, A., Mohamadkhani, P. (2008). [Mindfulness training as a clinical intervention (Persian)]. Mental health, 1(1), 29-38.

Pagnini, F. (2017). A telemedicine mindfulness-based intervention for people with multiple sclerosis and their caregivers. Retrieved from: https://clinicaltrials.gov/ct2/show/NCT02364505

Renton, T., Tang, H., Ennis, N., Cusimano, M. D., Bhalerao, S., Schweizer, T. A., et al. (2014). Web-based intervention programs for depression: A scoping review and evaluation. Journal of Medical Internet Research, 16(9), e209. [DOI:10.2196/jmir.3147] [PMID] [PMCID]
Segal, Z. V., \& Williams, T. D. (2002). Mindfulness-based cognitive therapy for depression. New York: Guilford Press.

Shirazi, E., Hakim Shooshtari, M., Shalbafan, M. R., Hadi, F., \& Bidaki R. (2017). [E-health, telemedicine and telepsychiatry (Persian)]. Iranian Journal of Psychiatry \& Clinical Psychology, 22(4), 266-9.

Ulrichsen, K. M., Kaufmann, T., Dørum, E. S., Kolskår, K. K., Richard, G., Alnæs, D., et al. (2016). Clinical utility of mindfulness training in the treatment of fatigue after stroke, traumatic brain injury and multiple sclerosis: A systematic literature review and meta-analysis. Frontiers in psychology, 7, 912. [DOI:10.3389/fpsyg.2016.00912] [PMID] [PMCID]

Wallin, M. T., Wilken, J. A., Turner, A. P., Williams, R. M., \& Kane, R. (2006). Depression and multiple sclerosis: Review of a lethal combination. The Journal of Rehabilitation Research and Development, 43(1), 45-62. [DOI:10.1682/JRRD.2004.09.0117] [PMID] 